\title{
Exposure to Fine Particulate Matter Air Pollution Alters mRNA and miRNA Expression in Bone Marrow-Derived Endothelial Progenitor Cells from Mice
}

\author{
Xiaohong Li ${ }^{1,2}$, Petra Haberzettl ${ }^{3,4}$, Daniel J. Conklin ${ }^{3,4}$, Aruni Bhatnagar ${ }^{3,4}$, Eric C. Rouchka ${ }^{2,5} \mathbb{D}$, Mei Zhang ${ }^{6}$ \\ and Timothy E. O'Toole ${ }^{3,4, *(1)}$ \\ 1 Department of Anatomical Sciences and Neurobiology, University of Louisville, Louisville, KY 40202, USA; \\ x0li0013@louisville.edu \\ 2 Kentucky Biomedical Research Infrastructure Network Bioinformatics Core, University of Louisville, \\ Louisville, KY 40202, USA; eric.rouchka@louisville.edu \\ 3 Christina Lee Brown Envirome Institute, University of Louisville, Louisville, KY 40202, USA; \\ petra.haberzettl@louisville.edu (P.H.); dj.conklin@louisville.edu (D.J.C.); \\ aruni.bhatnagar@louisville.edu (A.B.) \\ 4 Division of Environmental Medicine, University of Louisville, Louisville, KY 40202, USA \\ 5 Department of Computer Science and Engineering, University of Louisville, Louisville, KY 40202, USA \\ 6 Department of Medicine, University of Louisville Genomics Facility, Louisville, KY 40202, USA; \\ mei.zhang@louisville.edu \\ * Correspondence: tim.otoole@louisville.edu
}

\section{check for} updates

Citation: Li, X.; Haberzettl, P.; Conklin, D.J.; Bhatnagar, A.; Rouchka, E.C.; Zhang, M.; O'Toole, T.E. Exposure to Fine Particulate Matter Air Pollution Alters mRNA and miRNA Expression in Bone Marrow-Derived Endothelial Progenitor Cells from Mice. Genes 2021, 12, 1058. https://doi.org/ 10.3390/genes 12071058

Academic Editor: Kent M. Reed

Received: 28 May 2021

Accepted: 7 July 2021

Published: 10 July 2021

Publisher's Note: MDPI stays neutral with regard to jurisdictional claims in published maps and institutional affiliations.

Copyright: (c) 2021 by the authors. Licensee MDPI, Basel, Switzerland. This article is an open access article distributed under the terms and conditions of the Creative Commons Attribution (CC BY) license (https:/ / creativecommons.org/licenses/by/ $4.0 /)$.
Abstract: Exposure to fine particulate matter $\left(\mathrm{PM}_{2.5}\right)$ air pollution is associated with quantitative deficits of circulating endothelial progenitor cells (EPCs) in humans. Related exposures of mice to concentrated ambient $\mathrm{PM}_{2.5}$ (CAP) likewise reduces levels of circulating EPCs and induces defects in their proliferation and angiogenic potential as well. These changes in EPC number or function are predictive of larger cardiovascular dysfunction. To identify global, $\mathrm{PM}_{2.5}$-dependent mRNA and miRNA expression changes that may contribute to these defects, we performed a transcriptomic analysis of cells isolated from exposed mice. Compared with control samples, we identified 122 upregulated genes and 44 downregulated genes in EPCs derived from CAP-exposed animals. Functions most impacted by these gene expression changes included regulation of cell movement, cell and tissue development, and cellular assembly and organization. With respect to miRNA changes, we found that 55 were upregulated while 53 were downregulated in EPCs from CAP-exposed mice. The top functions impacted by these miRNA changes included cell movement, cell death and survival, cellular development, and cell growth and proliferation. A subset of these mRNA and miRNA changes were confirmed by qRT-PCR, including some reciprocal relationships. These results suggest that $\mathrm{PM}_{2.5}$-induced changes in gene expression may contribute to EPC dysfunction and that such changes may contribute to the adverse cardiovascular outcomes of air pollution exposure.

Keywords: air pollution; endothelial progenitor cell; cardiovascular disease

\section{Introduction}

Analysis of abundant epidemiological data has identified robust associations between exposure to fine particulate matter $\left(\mathrm{PM}_{2.5}\right)$ air pollution and adverse health outcomes in general [1], and cardiovascular disease in particular [2,3]. These studies have linked acute exposure to $\mathrm{PM}_{2.5}$ with an increased incidence of myocardial infarction, stroke, cardiac arrhythmias, and sudden cardiac death [3-5], while chronic exposures appear to accelerate the progression of atherosclerotic disease [6,7]. Physiologically, these adverse cardiovascular outcomes are likely a consequence of a damaged or dysfunctional endothelium. Not only does the endothelial layer provide a physical separation between blood and 
surrounding tissue, it also plays an essential role in immune responses, thrombosis, and the control of blood pressure. Thus, the maintenance of vascular homeostasis is essential for overall health.

As with other tissues, the endothelium is subjected to physiological and environmental stimuli that affect its viability and functionality. Maintenance and repair of the endothelium are believed to be accomplished in part by a group of stem cells, the endothelial progenitor cells (EPCs) [8]. While their exact phenotypic identity, origin, and location are somewhat uncertain [9], upon hypoxic signals, these cells are mobilized from storage niches, home to a site of tissue damage, and participate in its repair through terminal differentiation or by paracrine stimulation of wound healing processes $[10,11]$. Supporting this reparative role, it has been found that EPC levels in peripheral blood increase after myocardial infarction and stoke, and that suppressed levels of these cells in circulation are associated with increased risk of cardiovascular disease [12-14], and can be predictive of major adverse cardiovascular events and death [15]. Thus, an accessible supply of these cells is essential to maintain endothelial and overall health. However, several studies have shown that the abundance and functionality of EPCs can also be impacted by environmental cues. Previous studies from our group have shown that exposure of a young healthy cohort to episodic increases of $\mathrm{PM}_{2.5}$ or exposure of mice to concentrated ambient fine $\mathrm{PM}_{2.5}$ (CAP) results in decreases of circulating EPCs [16,17]. Furthermore, bone marrow-derived EPCs cultured from mice exposed to CAP demonstrate defects in proliferation, in vitro tube formation, and vascular repair in vivo [18]. Likewise, exposure to ozone, metals, cigarette smoke, and cigarette smoke constituents have all been shown to negatively impact EPC number or function [19-22]. Consistent with the CAP-induced changes in proliferation and angiogenic potential we previously observed, we also detected changes in the expression of specific genes regulating these processes using a targeted approach [18]. However, the extent of $\mathrm{PM}_{2.5}$-induced gene expression changes in EPCs is unknown and it is consequently not clear what other cellular functions might be affected by exposure. Likewise, there is little information regarding $\mathrm{PM}_{2.5}$-induced changes in miRNA expression. Mice have been commonly used to study the acute and chronic effects of $\mathrm{PM}_{2.5}$ exposure and they appropriately model human outcomes. Thus, in the current study, to gain insight into $\mathrm{PM}_{2.5}$-induced genomic expression changes in EPCs and identify early biomarkers of cardiovascular disease initiation or progression, we performed a global transcriptomic analysis of exposed mice. Our results identified differentially expressed mRNAs and miRNAs and those cellular functions impacted by these changes, further clarifying the mechanistic basis of $\mathrm{PM}_{2.5}$-induced cardiovascular disease.

\section{Materials and Methods}

\subsection{Mice, Exposures, and RNA Extraction}

Male C57BL/6J mice were obtained at 11 weeks of age from Jackson Laboratories and acclimated for 1 week in pathogen-free housing conditions. The animals were kept on a $12 \mathrm{~h}$ light/dark schedule and were supplied with food and water ad libitum. Mice $(n=3$; 1 cage) were randomly selected and exposed to CAP generated by a Versatile Aerosol Concentration and Enrichment System (VACES) in the Inhalation Facility of the University of Louisville, as previously described $[16,17]$. Mice exposed to HEPA-filtered air $(n=3$; 1 cage) were used as controls. Exposures to CAP or filtered air were $6 \mathrm{~h}$ per day ( 7 a.m. to 1 p.m.) for 30 consecutive days, and over this time course, the average CAP level was $67 \mu \mathrm{g} / \mathrm{m}^{3}$. These animals were monitored daily by veterinarian staff for well-being. The animals were euthanized (pentobarbitol injection (50 mg/kg, i.p., and exsanguination)) immediately after the final exposure (CAP- and air-exposed animals intermingled) and bone marrow cells isolated and EPCs cultured as previously described [18]. After 10 days in culture, the cells were harvested, and total RNA was isolated using the miRNeasy isolation kit (Qiagen). RNA quality was confirmed using an Agilent Bioanalyzer. A schematic of the experimental protocol illustrated in Figure 1. 


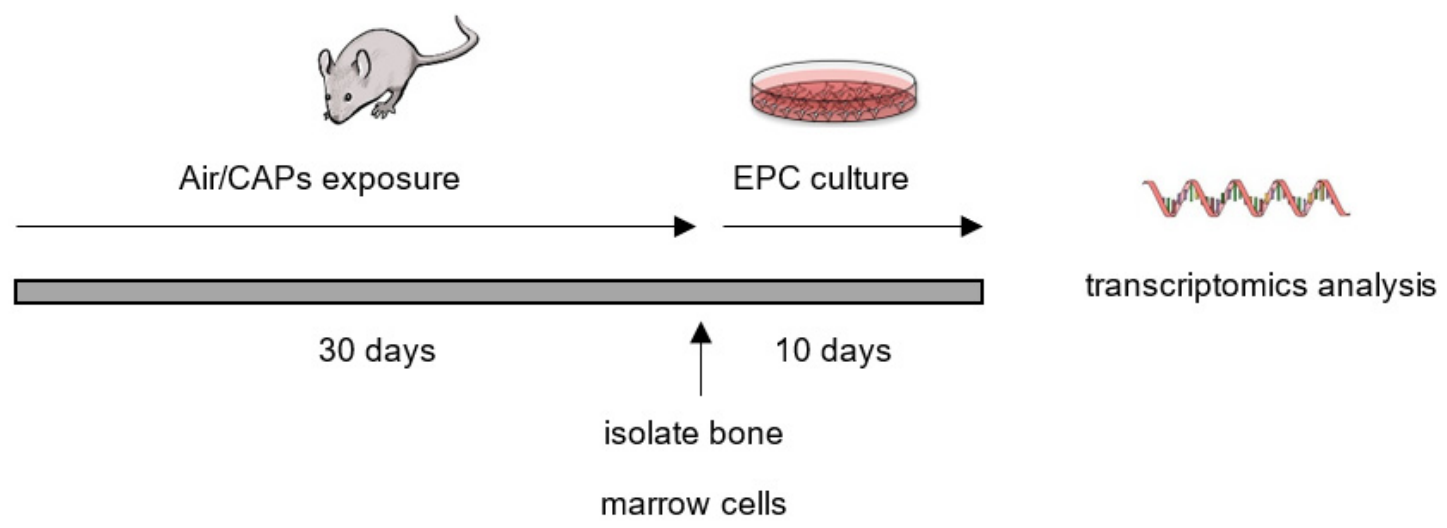

Figure 1. Experimental protocol. Illustrated is the timeline of animal treatment, cell culture, and RNA analysis.

\subsection{Next-Generation $m R N A$ Sequencing}

\subsubsection{Library Preparation}

Libraries were prepared using the TruSeq Stranded mRNA Library Prep kit (20020594, Illumina, San Diego, CA, USA). In brief, poly-A enrichment of RNA samples (250 ng) was accomplished in two purification steps using oligo dT beads. Purified mRNA was chemically fragmented through a heated digestion with divalent cations. Eluted samples were then used for first- and second-strand cDNA synthesis, and the resulting cDNA was isolated using Agencourt AMPure XP Beads (A63881, Beckman Coulter Life Sciences, Indianapolis, IN, USA). After adenylation of the $3^{\prime}$ end to prevent blunt end fragments from ligating to each other, dual-index adapters were ligated, and the samples were again purified with the same beads. Adapter ligated DNA fragments were then enriched and amplified with PCR to create the final cDNA libraries. The concentrations of these libraries were measured by Qubit dsDNA HS Assay Kit (Q32851, Invitrogen, Waltham, MA, USA), and their quality was assessed using the Agilent Bioanalyzer.

\subsubsection{Sequencing}

Similar molar amounts were pooled, and their quantity and quality were assessed using the MiSeq Reagent Nano Kit V2 (MS-103-1001, Illumina). The libraries and PhIX control (FC-110-3001, Illumina) were denatured and diluted using the manufacturer's directions and sequenced on an Illumina MiSeq. On the basis of the sequencing behavior of the libraries compared to PhIX, we re-pooled, denatured, and diluted equal amounts of the libraries, and $1.8 \mathrm{pM}$ was loaded on the NextSeq with $1 \%$ PhIX spike-in. After the first sequencing run, the libraries were re-pooled for a second run with the goal of having an equal number of reads per sample after results from both runs were combined, which gave an average of 35 million reads per sample. All sequencing was performed at the University of Louisville Genomics Facility on the Illumina NextSeq 500 using the NextSeq 500/550 75 cycle High Output Kit v2 (FC-404-2002, Illumina).

\subsubsection{Data Analysis}

The 48 fastq single-end raw sequencing files representing the air and CAP conditions with three biological replicates and eight lances per replicate were downloaded from Illumina's BaseSpace (https:/ / basespace.illumina.com/, accessed on 13 December 2019). The eight single-end raw fastq files across 8 sequencing lanes for each replicate designated L001 through L008 in the file names from the sequencing run were concatenated into one single-end fastq file using the unix cat command. Quality control (QC) of the raw sequence data was performed using FastQC (version 0.10.1). The FastQC results showed the sequences for all the samples had a Phred score above 30, which indicated $99.9 \%$ accuracy in base calling and were considered to be good quality. Therefore, sequence 
trimming was not performed. The concatenated sequence samples were directly aligned to the Mus musculus reference genome assembly (mm10.fa) using STAR (version 2.6) [23]. The alignment rate ranged from 99.12 to 99.98 percent across the samples. For the identification of differentially expressed genes (DEG) using DESeq2 [24], the raw reads counts were extracted from the STAR-aligned bam format files using HTSeq version 0.10 .0 and the Mus musculus gtf file (mm10.gtf). Supplementary Table S1 indicates the number of raw reads and number of reads successfully aligned for each of the six samples. The raw read counts for six samples being normalized using the relative log expression (RLE) method and then filtered to exclude genes with fewer than 10 counts across the samples with the aid of DESeq2. DEGs (CAP versus air) were identified and a Benjemini-Hochberg adjusted $p$-value ( $q$-value) cutoff $\leq 0.05$ with $\log _{2}$ fold change $(\mathrm{FC}) \geq 0.6$ was used to define differential expression. RNAseq data are available at GEO accession number GSE153038.

\subsection{Next-Generation miRNA Sequencing}

\subsubsection{Library Preparation}

Libraries were prepared with $100 \mathrm{ng}$ from each of the RNA samples using the QIAseq miRNA Library Kit (331502, Qiagen, Beverly, MA, USA) following the manufacturer's instructions. Briefly, specially designed $3^{\prime}$ and $5^{\prime}$ adapters were ligated to mature miRNAs. The ligated miRNAs were then reverse-transcribed to CDNA and purified with magnetic beads (QIAseq miRNA NGS beads). The eluted cDNA was amplified with a universal forward primer and a sample indexing reverse primer. The amplified libraries were again purified with magnetic beads to remove adapter dimers and unwanted RNA species. Library quantity and quality were analyzed on an Agilent Bioanalyzer using the Agilent high sensitivity DNA Kit (5067-4626, Agilent Technologies, Santa Clara, CA, USA).

\subsubsection{Sequencing}

Similar molar amounts of the libraries were pooled and run on MiSeq to test for quantity and quality. Then, the libraries and PhIX control (FC-110-3001, Illumina) were denatured and diluted following manufacturer's directions, and $300 \mu \mathrm{L}$ of each were combined and sequenced on Illumina MiSeq. The concentration of the libraries was corrected and the libraries re-pooled on the basis of the results from the initial MiSeq run. After denaturation and dilution, sequencing was performed on the University of Louisville Genomics Facility's Illumina NextSeq 500 using the NextSeq 500/550 75 cycle High Output Kit v2 (FC-404-2002, Illumina).

\subsubsection{Data Analysis}

The 48 fastq single-end raw sequencing files representing the air and CAP conditions with three biological replicates and eight lances per replicate were downloaded from Illumina's BaseSpace (https: / / basespace.illumina.com/, accessed on 3 January 2020). The eight single-end raw sequencing files (fastq) for each replicate designated L001 through L008 from the sequencing run were concatenated into one single-end fastq file using the unix cat command. Quality control $(\mathrm{QC})$ of the raw sequence data was performed using FastQC (version 0.10.1). The FastQC results indicated quality trimming was unnecessary since the minimum quality value of a Phred score for all samples was well above 30 (1 per 1000 error rate). Given this, preliminary adapter trimming was performed on each of the samples to remove the Qiagen $3^{\prime}$ and $5^{\prime}$ adapter sequence with Trimmomatric v0.33 [25]. For all of the samples, a unique peak around $22 \mathrm{bp}$ was identified that indicated that little if any other non-coding RNAs were selected in the library processing. As expected, this peak represented the length of the mature miRNAs. The data were further analyzed using mirDeep2 [26] and DESeq2 [24]. Briefly, the trimmed sequence reads were directly mapped to the mouse mm10 reference genome assembly using mirDeep2 package (v0.07) implementing bowtie mapper (v1.1.1) [27]. Supplementary Table S2 indicates the number of raw reads, number of reads after trimming, and number of reads successfully aligned for each of the six samples. The aligned sequences were then used as inputs into mirDeep2 
along with the latest release of the mirBase version 22 database (v22) containing mature miRNA and miRNA hairpin sequences. The result was a file containing the number of reads mapping to each of the 2061 mouse miRNAs. After quantification, the resulting counts for each miRNA in each sample were combined into a reads matrix. Using the counts table resulting from the previous step, we determined the differentially expressed miRNAs ( $q \leq 0.05$; upregulated: $\log _{2} \mathrm{FC} \geq 0.6$; downregulated: $\log _{2} \mathrm{FC}<-0.6$ ) using DESeq2. miRNA-seq data are available at GEO accession GSE153038.

\subsection{In Silico INGENUITY Network Analysis}

Canonical pathway and biological function analysis of DEGs and differentially expressed miRNAs (DE miRNAs) was performed using Ingenuity Pathway Analysis (202 Qiagen version 57662101).

\section{5. $q R T-P C R$}

Quantitative RT-PCR (qRT-PCR) of selected mRNA species was performed by initial, first-strand cDNA synthesis (High Capacity cDNA Reverse Transcription Kit, ThermoFisher), followed by real-time PCR using specific primers as recommended by the manufacturer (Supplementary Table S3: TaqMan gene expression assays, Thermo-Fisher). Quantitative RT-PCR of selected miRNA species was performed using specific TaqMan MicroRNA assays (Supplementary Table S3; Thermo-Fisher). All amplifications were performed on a Quant Studio 5 thermal cycler (Applied Biosystems). The internal controls used were Hprt for mRNAs and sno202 for miRNAs. Fold changes were calculated using the $\mathrm{Ct}$ method [28] and were reported with a standard error.

\section{Results}

\section{1. mRNA Analysis}

To evaluate similarities and differences in mRNA expression between the air and CAP groups, we initially performed a principal component analysis (PCA) on the relative log expression (RLE)-normalized counts of the six samples for all genes. In this analysis (Figure 2A), the two principal components (PC1 and PC2) represent two-dimensional data with $71.7 \%$ and $11.9 \%$ variation in the six mRNA samples, respectively. The PC1 axis (the first principal direction with all six mRNA samples) showed the largest variation, which explained most of the variance in the original data. The PC2 axis is the second most important direction and orthogonal to the PC1 axis. For these samples, the CAP group (blue) was partially separated from the air group (red), and some variation within the groups was observed.

To identify transcriptional alterations driven by CAP exposure, we performed mRNA expression profiling. Hierarchical clustering of the expression of 68 differentially expressed genes (DEGs) revealed a distinct transcriptomic profiling pattern between the samples as illustrated in a heatmap (Figure 2B) from low expression (green) to high expression (red). Given a $q$-value cutoff $\leq 0.05$, we identified 166 genes that were differentially expressed. This included 122 genes that were upregulated and 44 that were downregulated in the CAP vs. air groups. The most upregulated or downregulated DEGs are located in a volcano plot ( $p$-value vs. FC) in Figure 2C. We further analyzed these DEGs according to a fold change. Given a $q$-value $\leq 0.05$, we identified 104 that were upregulated by $>1.5$ fold $\left(\log _{2}\right.$ FC $\left.\geq 0.6\right)$. The top 20 of these genes are listed in Table 1, while the complete list is provided in Supplementary Table S4. Given a $q$-value $\leq 0.05$, we identified 34 that were downregulated by $<-1.5$ fold $\left(\log _{2} \mathrm{FC} \leq-0.6\right)$. The top 20 of these genes are listed in Table 2, while the complete list is provided in Supplementary Table S5. 
A.
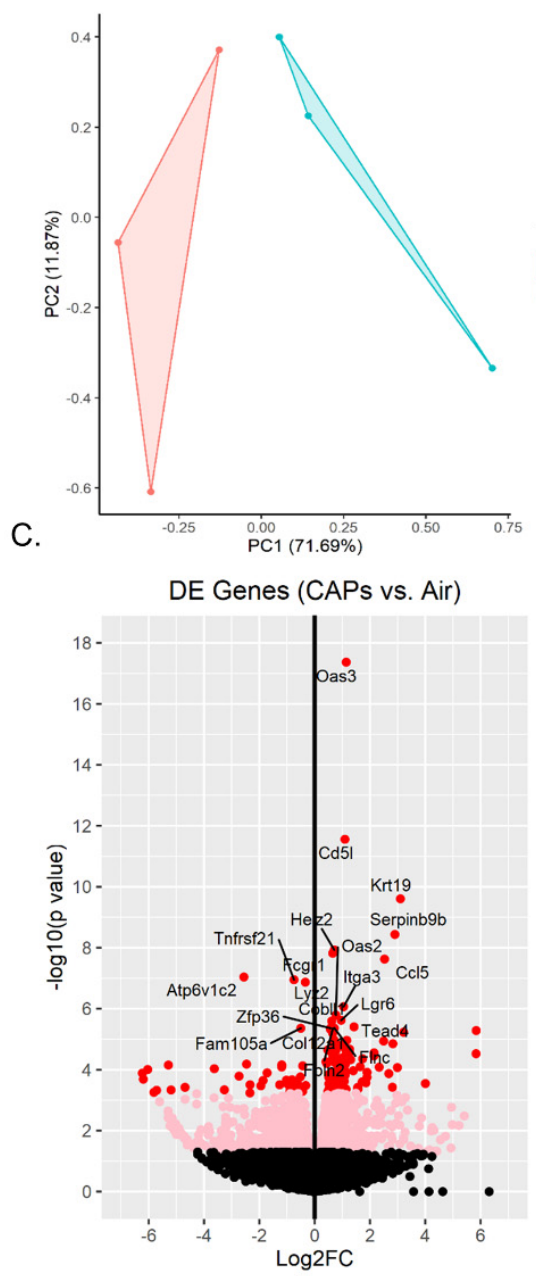

B.

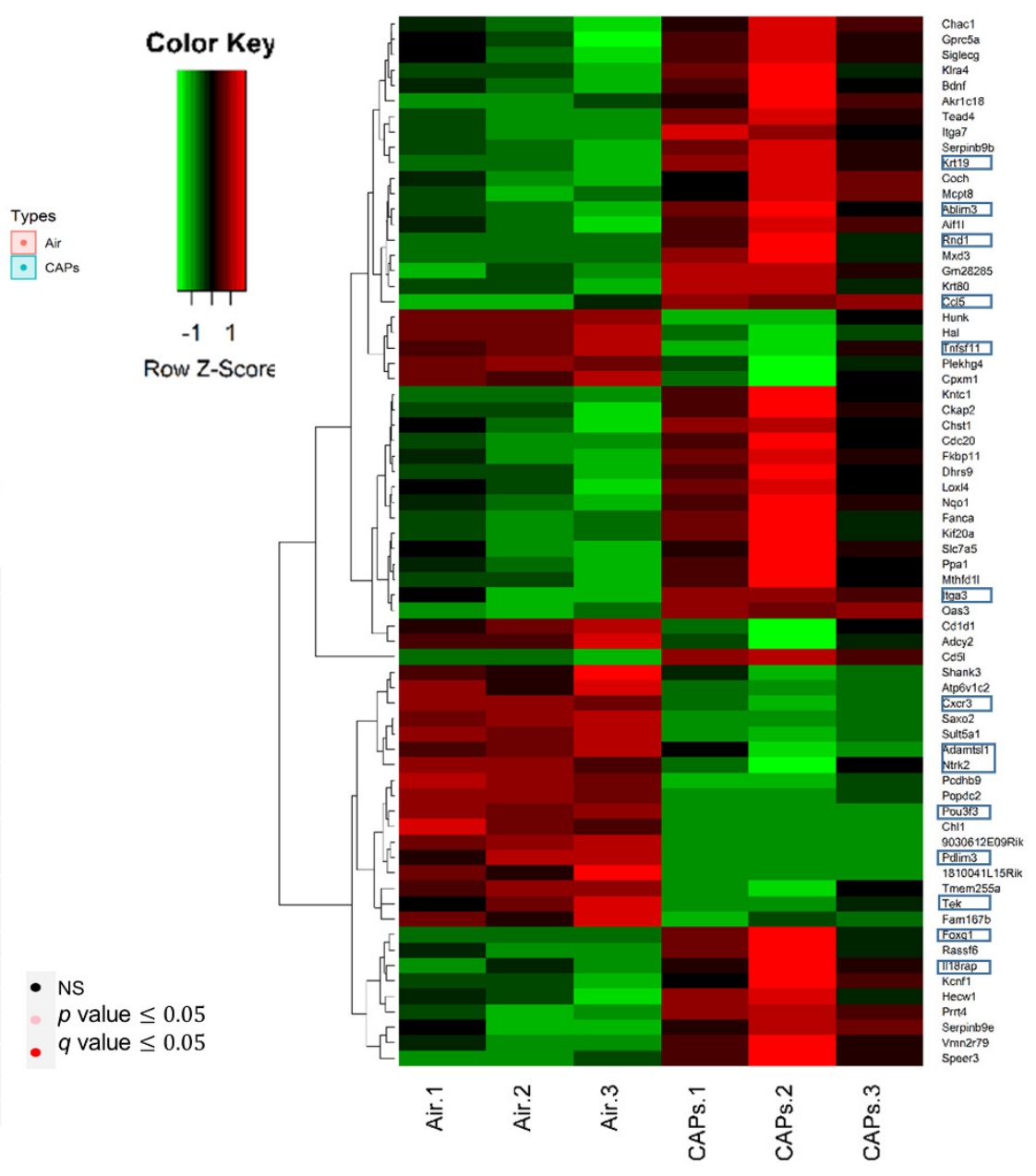

Figure 2. mRNA sequence analysis. Illustrated is a principal component analysis (PCA) for the analysis of mRNA (A), a heat map depicting 68 differentially expressed genes $\left(\mid \log _{2} \mathrm{FCl} \geq 1\right)$, where the Z-score values obtained by scaling the expression of the genes is denoted in a color code from lower (green) to higher (red) (B), and a volcano plot ( $\log _{2} \mathrm{FC}$ vs. $-\log 10$ ( $p$-value)) of DEGs (C). Boxed genes (B) are those that are implicated in EPC function.

Table 1. Upregulated genes.

\begin{tabular}{cccc}
\hline Ensemb1 ID & Gene Symbol (Description) & Log $_{\mathbf{2}}$ (FC) & $q$-Value \\
\hline ENSMUSG00000090362 & Vmn2r79 (vomeronasal 2, receptor 79) & 5.8 & $3.5 \times 10^{-3}$ \\
ENSMUSG00000067855 & Speer3 (spermatogenesis associated glutamate (E)-rich protein 3) & 5.8 & $1.1 \times 10^{-2}$ \\
ENSMUSG00000062342 & Serpinb9e (serine (or cysteine) peptidase inhibitor, clade B, member 9e) & 4.0 & $3.6 \times 10^{-2}$ \\
ENSMUSG00000020950 & Foxg1 (forkhead box G1) & 3.2 & $3.8 \times 10^{-3}$ \\
ENSMUSG00000020911 & Krt19 (keratin 19) & 3.1 & $1.2 \times 10^{-6}$ \\
ENSMUSG00000051726 & Kcnf1 (potassium voltage-gated channel, subfamily F, member 1) & 3.0 & $1.9 \times 10^{-2}$ \\
ENSMUSG00000021403 & Serpinb9b (serine (or cysteine) peptidase inhibitor, clade B, member 9b) & 2.9 & $1.3 \times 10^{-5}$ \\
ENSMUSG00000079654 & Prrt4 (proline-rich transmembrane protein 4) & 2.8 & $6.7 \times 10^{-3}$ \\
ENSMUSG00000021301 & Hecw1 (HECT, C2, and WW domain-containing E3 ubiquitin & 2.8 & $4.1 \times 10^{-2}$ \\
ENSMUSG00000029370 & protein ligase 1) & 2.7 & $2.4 \times 10^{-2}$ \\
ENSMUSG00000035042 & Rassf6 (Ras association (RalGDS/AF-6) domain family member 6) & 2.5 & $4.8 \times 10^{-5}$ \\
ENSMUSG00000054855 & Ccl5 (chemokine (C-C motif) ligand 5) & 2.5 & $6.3 \times 10^{-3}$ \\
ENSMUSG00000026068 & Rnd1 (Rho family GTPase 1) & 2.3 & $1.9 \times 10^{-2}$ \\
\hline
\end{tabular}


Table 1. Cont.

\begin{tabular}{cccc}
\hline Ensemb1 ID & Gene Symbol (Description) & Log $_{\mathbf{2}}$ (FC) & $\boldsymbol{q}$-Value \\
\hline ENSMUSG00000001864 & Aif1l (allograft inflammatory factor 1-like) & 2.1 & $1.0 \times 10^{-2}$ \\
ENSMUSG00000032735 & Ablim3 (actin binding LIM protein family, member 3) & 2.1 & $1.2 \times 10^{-2}$ \\
ENSMUSG00000020953 & Coch (cochlin) & 1.9 & $2.4 \times 10^{-2}$ \\
ENSMUSG00000037185 & Krt80 (keratin 80) & 1.9 & $2.8 \times 10^{-2}$ \\
ENSMUSG00000030468 & Siglecg (sialic acid binding Ig-like lectin G) & 1.9 & $3.6 \times 10^{-2}$ \\
ENSMUSG00000027313 & Chac1 (ChaC, cation transport regulator 1) & 1.7 & $1.4 \times 10^{-2}$ \\
ENSMUSG00000079852 & Klra4 (killer cell lectin-like receptor, subfamily A, member 4) & 1.7 & $3.4 \times 10^{-2}$ \\
\hline
\end{tabular}

Listed are the top 20 most upregulated genes $\left(q \leq 0.05 ; \log _{2} \mathrm{FC} \geq 0.6\right)$, sorted by $\log _{2} \mathrm{FC}$.

Table 2. Downregulated genes.

\begin{tabular}{lccc}
\hline Ensemb1 ID & Gene Symbol (Description) & Log $_{\mathbf{2}}$ (FC) & $q$-Value \\
\hline ENSMUSG00000030077 & Chl1 (cell adhesion molecule L1-like) & -6.2 & $2.4 \times 10^{-2}$ \\
ENSMUSG00000062760 & 1810041L15Rik (RIKEN cDNA 1810041L15 gene) & -6.2 & $3.1 \times 10^{-2}$ \\
ENSMUSG00000045515 & Pou3f3 (POU domain, class 3, transcription factor 3) & -6.0 & $2.1 \times 10^{-2}$ \\
ENSMUSG00000031636 & Pdlim3 (PDZ and LIM domain 3) & -5.8 & $4.9 \times 10^{-2}$ \\
ENSMUSG00000045008 & 9030612E09Rik (RIKEN cDNA 9030612E09 gene) & -5.7 & $4.6 \times 10^{-2}$ \\
ENSMUSG00000006386 & Tek (TEK receptor tyrosine kinase) & -5.3 & $1.8 \times 10^{-2}$ \\
ENSMUSG00000022803 & Popdc2 (popeye domain containing 2) & -5.2 & $4.5 \times 10^{-2}$ \\
ENSMUSG00000051242 & Pcdhb9 (protocadherin $\beta$ 9) & -4.7 & $4.1 \times 10^{-2}$ \\
ENSMUSG00000050493 & Fam167b (family with sequence similarity 167, member B) & -3.6 & $2.0 \times 10^{-2}$ \\
ENSMUSG00000036502 & Tmem255a (transmembrane protein 255A) & -3.3 & $4.5 \times 10^{-2}$ \\
ENSMUSG00000066113 & Adamtsl1 (ADAMTS-like 1) & -2.7 & $2.7 \times 10^{-2}$ \\
ENSMUSG00000020566 & Atp6v1c2 (ATPase, H+ transporting, lysosomal V1 subunit C2) & -2.6 & $1.6 \times 10^{-4}$ \\
ENSMUSG00000038570 & Saxo2 (stabilizer of axonemal microtubules 2) & -2.5 & $1.7 \times 10^{-2}$ \\
ENSMUSG00000055254 & Ntrk2 (neurotrophic tyrosine kinase, receptor, type 2) & -2.3 & $5.0 \times 10^{-2}$ \\
ENSMUSG00000000739 & Sult5a1 (sulfotransferase family 5A, member 1) & -2.3 & $3.7 \times 10^{-2}$ \\
ENSMUSG00000022623 & Shank3 (SH3 and multiple ankyrin repeat domains 3) & -1.9 & $3.8 \times 10^{-2}$ \\
ENSMUSG00000022015 & Tnfsf11 (tumor necrosis factor (ligand) superfamily, member 11) & -1.9 & $3.2 \times 10^{-2}$ \\
ENSMUSG00000027408 & Cpxm1 (carboxypeptidase X 1 (M14 family)) & -1.7 & $2.4 \times 10^{-2}$ \\
ENSMUSG00000050232 & Cxcr3 (chemokine (C-X-C motif) receptor 3) & -1.3 & $3.7 \times 10^{-2}$ \\
ENSMUSG00000053414 & Hunk (hormonally upregulated Neu-associated kinase) & -1.2 & $1.8 \times 10^{-2}$ \\
\hline
\end{tabular}

Listed are the top 20 most downregulated genes $\left(q \leq 0.05 ; \log _{2} \mathrm{FC}<-0.6\right)$, sorted by $\log _{2} \mathrm{FC}$.

\section{2. miRNA Analysis}

Using the same samples, we performed a similar analysis of miRNA expression. PCA analysis of these samples (Figure $3 \mathrm{~A}$ ) revealed $69.0 \%$ and $19.2 \%$ variation of the six miRNA samples. This analysis reveals clear separations between the CAP (blue) and air (red) samples. Hierarchical clustering of the expression of 38 differentially expressed miRNAs (DE miRNAs) revealed a unique miRNA profiling pattern, as illustrated in a heatmap (Figure 3B). Given a $q$-value cutoff $\leq 0.05$, we identified 108 unique miRNAs that were differentially expressed. This included 55 miRNAs that were upregulated and 53 that were downregulated in the CAP vs. air groups. The most upregulated and downregulated miRNAs are located in a volcano plot (Figure 3C). We further analyzed these DE miRNAs according to fold change. Given a $q$-value $\leq 0.05$, we identified 19 that were upregulated by $>1.5$ fold $\left(\log _{2} \mathrm{FC} \geq 0.6\right)$ and 19 that were downregulated by $>1.5$ fold $\left(\log _{2} \mathrm{FC} \leq-0.6\right)$. These miRNAs are listed in Table 3. 
A.

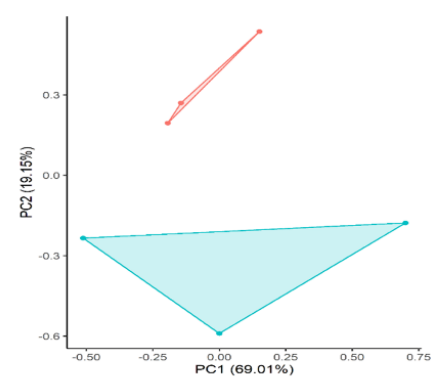

C.

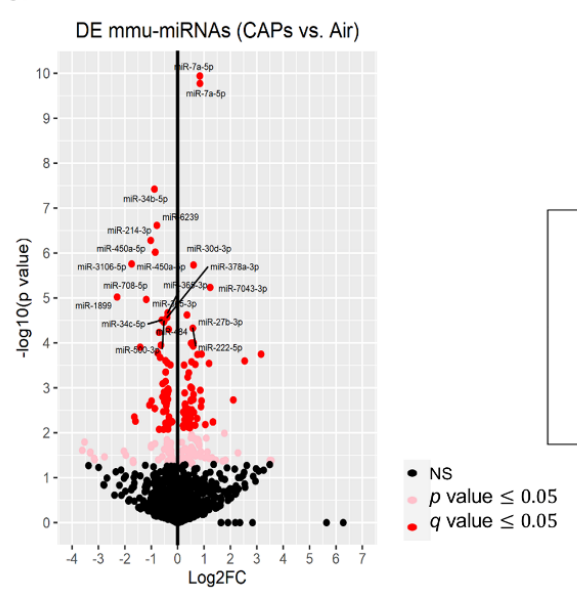

B.
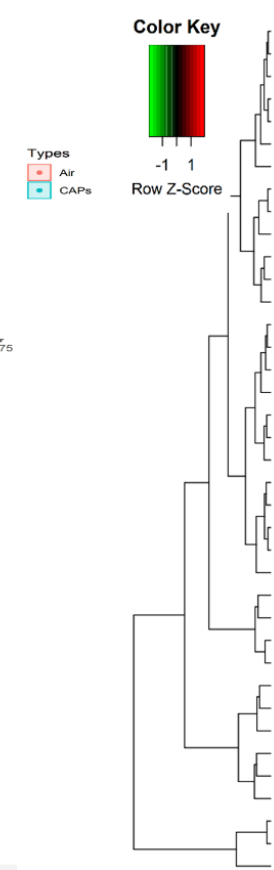

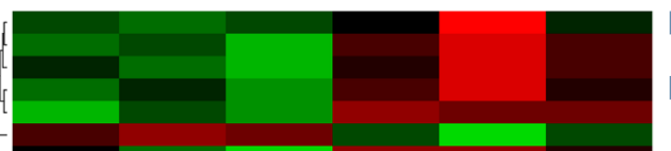

$\frac{\mid m m u-m i R-922-3 p}{\text { mmu-miR-466- }}$ Mmu-mir-466k
mmu-mir-466h-5p $\frac{m \text { mmu-miR-342-5p }}{\text { mmu-miR-30d-30 }}$ mmu-miR-450a-5p mmu-miR-7043-3p mmu-miR. 6239 mmu-miR-188-3p mmu-miR-3969
mmu-miR-450a-2-3p mmu-mir-708-3p mmu-mirR-708-3p mmu-miR-499-5p mmu-mir-3110-5p mmu-miR-700-5p mmu-miR-5619-5p mmu-miR-7b-5p mmu-miR - $7654-5 p$
mmu-miR-376b-3p mmu-miR-376b-3p
mmu-miR-3473a mmu-mir-3473a
mmu-miR-200c-3p Mmu-miR-200c-3p
mmu-miR-23a-5p mmu-miR-23a-5p mmu-mir-365-2-5p mmu-mirR-6539 mmu-mir-322-3p mmu-miR-27a-5p
mmu-miR-511-3p

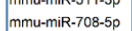

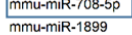
mmu-miR-486a-3p mmu-miR-7649-3p
mmu-miR-344d-3p mmu-miR-6937-5p mMu-miR-6937-5 Mmu-miR -6399
mmu-miR-34b-5p mmu-miR-34b-5p $m$ mu-mik.-214.-3p
mmu-miR-7a-5p

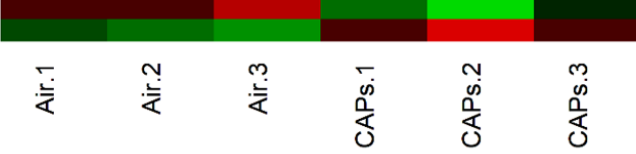

Figure 3. miRNA sequence analysis. Illustrated is a principal component analysis (PCA) for the analysis of miRNA (A), a heat map depicting 38 differentially expressed miRNAs $\left(\left|\log _{2} \mathrm{FC}\right| \geq 0.6\right.$ where the Z-score values obtained from scaling the expression of the miRNAs is denoted in a color code from lower (green) to higher (red) (B), and a volcano plot $\left(\log _{2} \mathrm{FC}\right.$ vs. $-\leq \log 10$ ( $p$-value)) of the DE miRNAs (C). Boxed miRNAs $(\mathbf{B})$ are those that are implicated in EPC function.

Table 3. Upregulated and downregulated miRNAs.

\begin{tabular}{|c|c|c|c|c|c|}
\hline \multicolumn{3}{|c|}{ Upregulated } & \multicolumn{3}{|c|}{ Downregulated } \\
\hline miRNA & FC $\left(\log _{2}\right)$ & $q$ Value & miRNA & FC $\left(\log _{2}\right)$ & $q$ Value \\
\hline mmu-miR-6937-5p & 3.2 & $1.8 \times 10^{-4}$ & mmu-miR-1899 & -2.3 & $6.8 \times 10^{-4}$ \\
\hline mmu-miR-6399 & 2.5 & $2.5 \times 10^{-4}$ & mmu-miR-3106-5p & -1.7 & $1.6 \times 10^{-4}$ \\
\hline mmu-miR-6539 & 2.1 & $1.9 \times 10^{-3}$ & mmu-miR-486a-3p & -1.6 & $3.4 \times 10^{-2}$ \\
\hline mmu-miR-344d-3p & 1.3 & $5.7 \times 10^{-3}$ & mmu-miR-7649-3p & -1.6 & $3.6 \times 10^{-2}$ \\
\hline mmu-miR-7043-3p & 1.2 & $5.8 \times 10^{-6}$ & mmu-miR-3969 & -1.4 & $2.9 \times 10^{-3}$ \\
\hline mmu-miR-23a-5p & 1.2 & $2.9 \times 10^{-4}$ & mmu-miR-708-5p & -1.2 & $7.0 \times 10^{-4}$ \\
\hline mmu-miR-27a-5p & 1.0 & $6.6 \times 10^{-3}$ & mmu-miR-708-3p & -1.1 & $2.3 \times 10^{-2}$ \\
\hline mmu-miR-7b-5p & 0.9 & $1.8 \times 10^{-4}$ & mmu-miR-499-5p & -1.1 & $2.3 \times 10^{-2}$ \\
\hline mmu-miR-365-2-5p & 0.9 & $1.9 \times 10^{-3}$ & mmu-miR-214-3p & -1.0 & $8.2 \times 10^{-5}$ \\
\hline mmu-miR-376b-3p & 0.9 & $2.6 \times 10^{-3}$ & mmu-miR-5619-5p & -1.0 & $2.1 \times 10^{-2}$ \\
\hline mmu-miR-3473a & 0.9 & $1.1 \times 10^{-3}$ & $m m u-m i R-34 b-5 p$ & -0.9 & $9.9 \times 10^{-6}$ \\
\hline mmu-miR-7a-5p & 0.8 & $1.2 \times 10^{-10}$ & mmu-miR-3110-5p & -0.9 & $2.6 \times 10^{-2}$ \\
\hline mmu-miR-342-5p & 0.8 & $1.8 \times 10^{-4}$ & mmu-miR-450a-5p & -0.8 & $1.1 \times 10^{-4}$ \\
\hline mmu-miR-7654-5p & 0.7 & $4.8 \times 10^{-3}$ & mmu-miR-6239 & -0.8 & $4.7 \times 10^{-5}$ \\
\hline mmu-miR-466h-5p & 0.7 & $3.0 \times 10^{-4}$ & mmu-miR-450a-2-3p & -0.8 & $3.8 \times 10^{-3}$ \\
\hline mmu-miR-92a-3p & 0.7 & $6.8 \times 10^{-3}$ & mmu-miR-700-5p & -0.7 & $4.6 \times 10^{-2}$ \\
\hline mmu-miR-200c-3p & 0.6 & $3.5 \times 10^{-3}$ & mmu-miR-188-3p & -0.7 & $2.1 \times 10^{-3}$ \\
\hline mmu-miR-466k & 0.6 & $1.0 \times 10^{-4}$ & mmu-miR-511-3p & -0.7 & $4.3 \times 10^{-3}$ \\
\hline mmu-miR-30d-3p & 0.6 & $1.9 \times 10^{-6}$ & mmu-miR-322-3p & -0.6 & $2.8 \times 10^{-3}$ \\
\hline mmu-miR-877-3p & 0.6 & $1.4 \times 10^{-3}$ & & & \\
\hline
\end{tabular}

Listed are the most upregulated and downregulated miRNAs ( $q \leq 0.05$; upregulated: $\log _{2} \mathrm{FC} \geq 0.6$; $\left.\operatorname{downregulated}_{\mathrm{f}} \log _{2} \mathrm{FC}<-0.6\right)$, sorted by $\log _{2} \mathrm{FC}$. 


\subsection{Biological Function Analysis}

To identify biological functions involving the DEGs and DE miRNAs, we used ingenuity pathway analysis (IPA). For the 166 DEGs, we found the most impacted, biological functions involved cellular movement, tissue development, cardiovascular system development and function, cellular assembly and organization, and cellular function and maintenance (Table 4). Other functions implicated to a lesser extent were those involving metabolic processes and signal transduction. Similarly, many of the $108 \mathrm{DE}$ miRNAs were predicted to be involved in functions involved in cell movement, survival, development, growth, cardiovascular system development and function, signaling, and organization (Table 5).

Table 4. Biological functions-mRNAs.

\begin{tabular}{|c|c|c|c|}
\hline Category & $p$-Value & Number & Representative Genes \\
\hline Cellular movement & $1.53 \times 10^{-10}-2.52 \times 10^{-4}$ & 56 & $\begin{array}{c}\text { Ccl5, Foxg1, Itga3, Krt19, Marcks, Tek, } \\
\text { Tgfb2, Tnsf11 }\end{array}$ \\
\hline Tissue development & $4.43 \times 10^{-10}-2.33 \times 10^{-4}$ & 66 & $\begin{array}{c}\text { Ccl5, Dusp-10, Foxg1, Itga3, Krt19, Marcks, Myc, } \\
\text { Ntrk2, Tnfsf11 }\end{array}$ \\
\hline $\begin{array}{l}\text { Cardiovascular system } \\
\text { development and function }\end{array}$ & $1.42 \times 10^{-9}-2.5 \times 10^{-4}$ & 37 & $\begin{array}{c}\text { Ccl5, Cxcr3, Itga3, Myc, Ntrk2, Rnd1, Tek, } \\
\text { Tgfb2, Tnsf11 }\end{array}$ \\
\hline $\begin{array}{l}\text { Cellular assembly and } \\
\text { organization }\end{array}$ & $1.03 \times 10^{-8}-1.94 \times 10^{-4}$ & 43 & $\begin{array}{c}\text { Ccl5, Cxcr3, Itga3, Krt19, Myc, Ntrk2, Pdlim3, } \\
\text { Rnd1, Tek, Tgfb2, Tnfsf11 }\end{array}$ \\
\hline $\begin{array}{l}\text { Cellular function and } \\
\text { maintenance }\end{array}$ & $1.03 \times 10^{-8}-1.94 \times 10^{-4}$ & 39 & $\begin{array}{c}\text { Ablim3, Ccl5, Cxcr3, Itga3, Myc, Ntrk2, Rnd1, } \\
\text { Tek, Tgfb2, Tnfsf11 }\end{array}$ \\
\hline Cellular development & $1.44 \times 10^{-7}-1.99 \times 10^{-4}$ & 52 & $\begin{array}{c}\text { Ccl5, Chl1, Cxcr3, Dusp10, Foxg1, Itga3, Marcks, } \\
\text { Myc, Ntrk2, Tek, Tgfb2, Tnfsf11 }\end{array}$ \\
\hline Cellular growth and proliferation & $1.44 \times 10^{-7}-2.04 \times 10^{-4}$ & 61 & $\begin{array}{l}\text { Ccl5, Chl1, Cxcr3, Dusp-10, Foxg1, Il18rap, Itga3, } \\
\text { Marcks, Myc, Ntrk2, Tek, Tgfb2, Tnfsf11 }\end{array}$ \\
\hline Cell death and survival & $2.53 \times 10^{-7}-2.39 \times 10^{-4}$ & 56 & $\begin{array}{l}\text { Ccl5, Chl1, Cxcr3, Dusp-10, Foxg1, Itga3, Myc, } \\
\text { Ntrk2, Pou3f3, Tek, Tgfb2, Tnfsf11 }\end{array}$ \\
\hline Connective tissue disorders & $3.02 \times 10^{-7}-1.99 \times 10^{-4}$ & 43 & $\begin{array}{c}\text { Adamts11, Ccl5, Cxcr3, Dusp-10, Ntrk2, } \\
\text { Tgfb2, Tnfsf11 }\end{array}$ \\
\hline $\begin{array}{l}\text { Cell-to-cell signaling and } \\
\text { interaction }\end{array}$ & $3.38 \times 10^{-7}-2.47 \times 10^{-4}$ & 31 & Ccl5, Cxcr3, Itga3, Ntrk2, Tek, Tgfb2, Tnfsf11 \\
\hline Cell cycle & $6.15 \times 10^{-7}-2.29 \times 10^{-4}$ & 19 & Ccl5, Foxg1, Myc, Ntrk2, Tnfsf11 \\
\hline Tissue morphology & $8.46 \times 10^{-7}-1.89 \times 10^{-4}$ & 53 & $\begin{array}{c}\text { Cc15, Cxcr3, Dusp-10, Itga3, Krt19, Myc, Ntrk2, } \\
\text { Tek, Tgfb2, Tnfsf11 }\end{array}$ \\
\hline Cell morphology & $2.67 \times 10^{-6}-1.89 \times 10^{-4}$ & 38 & $\begin{array}{c}\text { Ablim3, Ccl5, Chl1, Cxcr3, Foxg1, Itga3, Myc, } \\
\text { Ntrk2, Pou3f3, Tek, Tgfb2, Tnfsf11 }\end{array}$ \\
\hline Post-translational modification & $2.73 \times 10^{-6}-2.46 \times 10^{-4}$ & 20 & Ccl5, Ntrk2, Tek, Tgfb2, Tnfsf11 \\
\hline $\begin{array}{l}\text { Connective tissue development } \\
\text { and function }\end{array}$ & $1.24 \times 10^{-5}-1.89 \times 10^{-4}$ & 17 & Cxcr3, Myc, Tgfb2, Tnfsf11 \\
\hline $\begin{array}{l}\text { DNA replication, recombination, } \\
\text { and repair }\end{array}$ & $2.22 \times 10^{-5}-1.52 \times 10^{-4}$ & 15 & Ccl5, Cxcr3, Myc, Ntrk2, Tgfb2, Tnfsf11 \\
\hline Hematopoiesis & $2.41 \times 10^{-5}-1.68 \times 10^{-4}$ & 29 & Ccl5, Cxcr3, Dusp-10, Marcks, Myc, Tek, Tnfsf11 \\
\hline Amino acid metabolism & $\leq 9.78 \times 10^{-5}$ & 3 & Мус \\
\hline Molecular transport & $9.78 \times 10^{-5}-2.29 \times 10^{-4}$ & 15 & Ccl5, Cxcr3, Myc, Tnfsf11 \\
\hline Small molecule biochemistry & $9.78 \times 10^{-5}-2.29 \times 10^{-4}$ & 6 & Myc, Tnfsf11 \\
\hline Energy production & $\leq 2.29 \times 10^{-4}$ & 4 & Tnfsf11 \\
\hline Nucleic acid metabolism & $\leq 2.29 \times 10^{-4}$ & 4 & Tnfsf11 \\
\hline Cell signaling & $\leq 2.46 \times 10^{-4}$ & 7 & Ccl5 \\
\hline
\end{tabular}

Listed are the top biological functions impacted by the mRNA changes we detected, their significance, the number of DEGs that impact these functions, and representative DEGs as listed in Supplementary Tables S4 and S5. Selected genes are boxed in Figure 2B. 
Table 5. Biological functions-miRNAs.

\begin{tabular}{|c|c|c|c|}
\hline Category & $p$-Value & Number & Representative miRNA \\
\hline Cellular movement & $1.18 \times 10^{-6}-4.59 \times 10^{-2}$ & 16 & $\operatorname{mir}-7 a-5 p, \operatorname{mir}-92 a-3 p$ \\
\hline Cell death and survival & $1.71 \times 10^{-6}-4.59 \times 10^{-2}$ & 16 & $\operatorname{mir}-214-3 p$ \\
\hline Cellular development & $3.45 \times 10^{-5}-4.15 \times 10^{-2}$ & 21 & $\operatorname{mir}-27 a-3 p$, mir-92a-3p \\
\hline Cellular growth and proliferation & $3.45 \times 10^{-5}-3.65 \times 10^{-2}$ & 16 & $\operatorname{mir}-27 a-3 p, \operatorname{mir}-92 a-3 p$ \\
\hline $\begin{array}{c}\text { Cardiovascular system development } \\
\text { and function }\end{array}$ & $1.95 \times 10^{-4}-3.9 \times 10^{-2}$ & 14 & $\begin{array}{c}\operatorname{mir}-27 a-3 p, \operatorname{mir}-214-3 p, \operatorname{mir}-486-3 p, \\
\text { mir-34a-5p }\end{array}$ \\
\hline Cell cycle & $3.61 \times 10^{-4}-4.48 \times 10^{-2}$ & 6 & $\operatorname{mir}-27 a-3 p$ \\
\hline Cell morphology & $5.51 \times 10^{-3}-3.9 \times 10^{-2}$ & 5 & $\operatorname{mir}-214-3 p$ \\
\hline Cell-to-cell signaling and interaction & $1.37 \times 10^{-2}-2.46 \times 10^{-2}$ & 5 & $\operatorname{mir}-34 a-5 p$ \\
\hline Cellular assembly and organization & $1.37 \times 10^{-2}-4.85 \times 10^{-2}$ & 3 & $\operatorname{mir}-708-5 p$ \\
\hline Cellular function and maintenance & $1.37 \times 10^{-2}-3.53 \times 10^{-2}$ & 6 & $\operatorname{mir}-34 a-5 p$ \\
\hline
\end{tabular}

Listed are the top 10 biological functions impacted by the miRNA changes we detected, their significance, the number of DE miRNAs that impact these functions, and representative miRNAs as listed in Table 3. Selected miRNAs are boxed in Figure 3B.

\section{4. qRT-PCR Validation}

To validate results from our transcriptomics analysis, we performed qRT-PCR for a subset of differentially expressed mRNAs (Figure 4, Table 6) that are involved in those functions identified in the IPA analysis (Table 4). We also performed a similar qRT-PCR analysis of selected DE miRNAs (Figure 4, Table 6). Our results both confirmed the direction of change (upregulated vs. downregulated) and had a high level of consistency with regards to the extent of the change (fold change). Since there is a reciprocal relationship between miRNA expression and the expression of their target mRNAs, we sought to confirm some of these relationships among our DEGs and DE-miRNAs. Consistent with prior reports [29-32], our RNA-seq data and our qRT-PCR results confirmed reciprocal relationships between mir-214-3p and Ccl5, mir-450a-5p and Dusp-10, and mir-92a-3p and Tgfb2 (Figure 4, Table 7). Finally, we used a bioinformatics database [30] to identify additional, documented, reciprocal relationships between the 166 DEGs and the $108 \mathrm{DE}$ miRNAs (Figure 5). Our detected changes in the levels of mir-7b-5p, mir-466k, mir-499$5 p$, mir-11-3p, mir-3110-5p, mir-34b-5p, and mir-450a-5p (Table 3) were consistent with the inverse expression levels of some target mRNAs, further supporting the validity of our data.

A

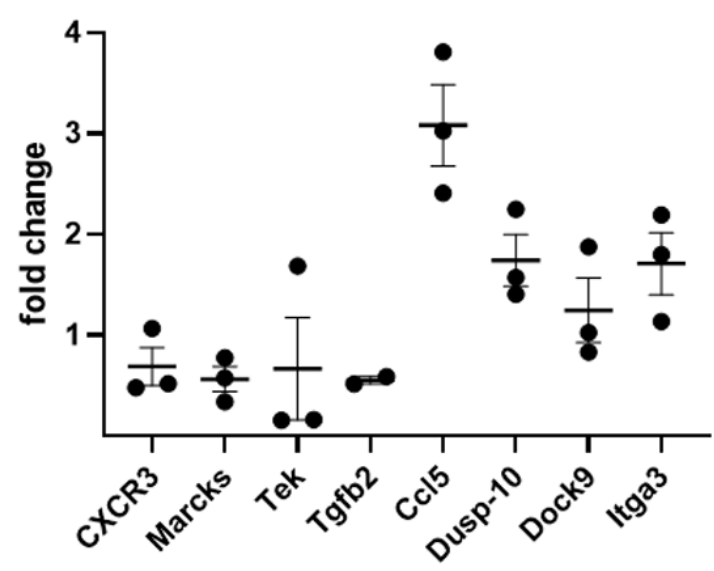

B

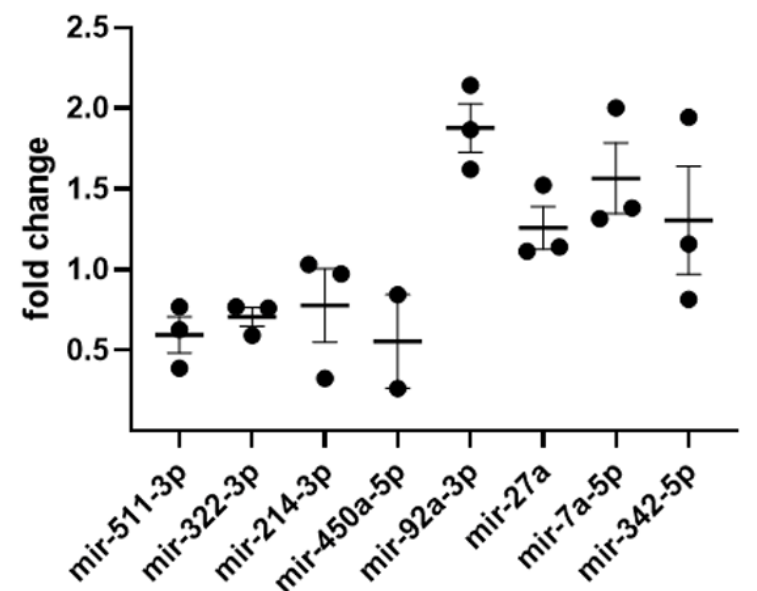

Figure 4. rtPCR confirmation. Illustrated are the fold changes for selected, differentially expressed mRNAs (A) or miRNAs (B) as determined by qRT-PCR. Downregulated RNAs have an average fold change $<1$, while upregulated RNAs have a fold change $>1$. 
Table 6. Confirmation of RNA-seq results.

\begin{tabular}{ccc}
\hline DEG & FC-RNA-Seq & FC-qRT-PCR (SE) \\
\hline Cxcr3 & 0.406 & $0.687(0.192)$ \\
Marcks & 0.550 & $0.563(0.128)$ \\
Tek & 0.025 & $0.666(0.517)$ \\
Dock9 & 1.66 & $1.24(0.330)$ \\
Itga3 & 2.07 & $1.71(0.313)$ \\
\hline DE miRNA & FC-RNA-Seq & FC-qRT-PCR (SE) \\
mir-511-3p & 0.630 & $0.595(0.113)$ \\
mir-322-3p & 0.64 & $0.707(0.059)$ \\
mir-27a & 2.28 & $1.26(0.134)$ \\
mir-342-5p & 1.69 & $1.31(0.340)$ \\
mir-7a-5p & 1.79 & $1.57(0.222)$ \\
\hline
\end{tabular}

Listed are representative DEGs or DE miRNAs and their fold changes (FC), as determined by RNA-seq analysis and qRT-PCR $(n=9)$.

Table 7. Confirmation of reciprocal mRNA-miRNA relationships.

\begin{tabular}{cccccc}
\hline & \multicolumn{2}{c}{ Representative Gene } & \multicolumn{2}{c}{ Representative Reciprocal miRNA } \\
\hline \multirow{2}{*}{ Gene } & $\begin{array}{c}\text { FC-RNA- } \\
\text { seq }\end{array}$ & $\begin{array}{c}\text { FC-qRT-PCR } \\
\text { (SE) }\end{array}$ & miRNA & $\begin{array}{c}\text { FC-RNA- } \\
\text { Seq }\end{array}$ & $\begin{array}{c}\text { FC-qRT-PCR } \\
\text { (SE) }\end{array}$ \\
\hline Ccl5 & 5.75 & $3.08(0.412)$ & mir-214-3p & 0.493 & $0.778(0.226)$ \\
Dusp-10 & 1.81 & $1.74(0.26)$ & mir-450a-5p & 0.555 & $0.560(0.241)$ \\
Tgfb2 & 0.535 & $0.551(0.029)$ & mir-92a-3p & 1.58 & $1.88(0.15)$ \\
\hline
\end{tabular}

Listed are representative DEGs, a representative targeting DE miRNA, and their respective fold changes (FC) as determined by RNA-seq analysis and qRT-PCR ( $n=9$ samples).

Validated gene targets of the DE mRNAs-miRNAs pairs
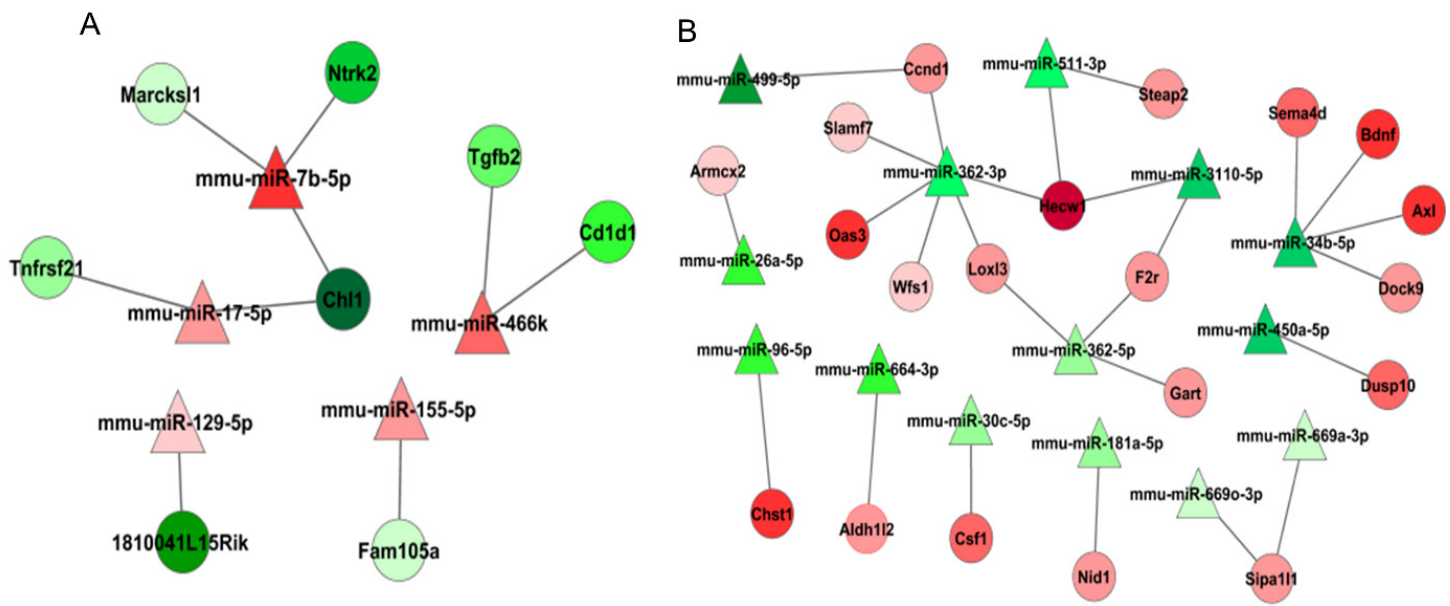

Figure 5. mRNA-miRNA relationships. Illustrated are documented, inverse mRNA-miRNA relationships consistent with the changes in EPCs we identified. (A) Downregulated mRNAs (green) and upregulated miRNAs (red); (B) upregulated mRNAs (red) and downregulated miRNAs (green). Color shade (darkest to lightest) is indicative of relative FC (greatest to least).

\section{Discussion}

Exposure to $\mathrm{PM}_{2.5}$ is associated with cardiovascular morbidity and mortality in humans [2,3] and promotes pre-clinical vascular disease in animal models of exposure [33-35]. Some studies propose that quantitative $[16,17,36,37]$ or qualitative [18] defects in EPCs may underlie these outcomes. Yet the mechanistic basis for $\mathrm{PM}_{2.5}$-mediated EPC depletion or dysfunction is not completely understood. To this end, in this study, we used a transcriptomic approach to identify gene expression changes in EPCs isolated from the bone 
marrow of mice exposed to CAP. Compared with control cells isolated from mice breathing filtered air, we identified multiple mRNAs and miRNAs that were either upregulated or downregulated in exposed mice. The top predicted biological functions impacted by these changes are those involving cell movement, cell and tissue development, cell death and survival, and cellular assembly and organization. These predictions are consistent with the role of EPCs in vascular maintenance and repair, and with previously identified, CAP-induced impairments in proliferation, in vitro tube formation, and angiogenesis [18]. Thus, these $\mathrm{PM}_{2.5}$-induced changes in EPC gene expression may form the basis of EPC defects and be early indices of incipient cardiovascular disease.

Multiple mechanisms may contribute to the gene expression changes we observed. Epigenetic modifications are implicated, given that the RNA samples used for transcriptomics analysis were isolated from EPCs after 10 days of culture following bone marrow collection from exposed mice. One possible epigenetic mechanism is the post-transcriptional regulation of mRNA levels through targeting miRNAs. Consistent with this idea, we did identify reciprocal relationships between representative dysregulated genes and at least one of their documented, targeting miRNAs (Table 7). Supporting this mechanism of $\mathrm{PM}_{2.5}$-induced gene expression changes, other studies also suggested that particle inhalation [38,39] or exposure to particles in cell culture models $[40,41]$ induces the upregulation or downregulation of specific miRNAs. Other epigenetic mechanisms may involve the modification of nuclear material. Methylation of cytosine residues in DNA promoter regions generally inhibits gene expression [42]. In support of this mechanism, some prior studies have determined that exposure to $\mathrm{PM}_{2.5}$ induces site-specific DNA methylation, thereby limiting mRNA and protein expression [43-45]. DNA methylation is catalyzed by the family of DNA methyltransferases (DNMTs) and, consistently, prior evidence also suggested that $\mathrm{PM}_{2.5}$ exposure can activate DNMTs [46]. Furthermore, it has also been shown that reactive oxygen species (ROS) can upregulate DNMT expression [47]. As ROS production is an early and robust outcome of $\mathrm{PM}_{2.5}$ inhalation [48], such exposures can thus effectively regulate DNMT expression or activity in promoting methylation. The regulation of gene expression through promoter DNA methylation may be a common outcome of exposure to other environmental toxins as well, and has also been reported following exposure to cigarette smoke [49], volatiles [50], or metals [51], which can also be a constituent of air pollution particles. Finally, in addition to DNA modifications, histone modifications (e.g., methylation, acetylation) can alter chromatin structure, thereby facilitating or impairing transcriptional processes [42]. Recent evidence likewise suggests $\mathrm{PM}_{2.5}$ may promote histone acetylation and that this may be accomplished in a dose- and time-dependent manner [52,53].

Exposure to $\mathrm{PM}_{2.5}$ is known to negatively impact vascular function and/or the ability of EPCs to maintain vascular homeostasis [18,33,34]. This is supported by our function analysis in the current study, which suggested the influence of $\mathrm{PM}_{2.5}$ on genes that regulate cardiovascular system development and function. Furthermore, some of the specific gene expression changes we observed are consistent with $\mathrm{PM}_{2.5}$-induced impairments in EPC function. EPC-expressed Cxcr3 is a receptor for multiple CXC chemokines that collectively promote the mobilization, migration, and homing of these cells [54,55]. We found that Cxcr3 is downregulated in EPCs from CAP-exposed mice (Tables 2 and 6), thus potentially limiting the availability of these cells for the repair of distal tissue damage. Other gene expression changes we observed are consistent with an impairment in EPC differentiation. For instance, signaling through the angiopoietin receptor Tek (Tie2), a commonly used marker of mature EPCs, is important in controlling the differentiation of these cells [56]. Its downregulation (Tables 2 and 6) suggests inefficient EPC maturation in exposed animals. Among its effects, the proto-oncogene Myc appears to support cellular de-differentiation and, indeed, was one of the original factors used in the generation of induced pluripotent stem cells [57]. Its upregulation in our study (Supplementary Table S4) further suggests a mechanism whereby $\mathrm{PM}_{2.5}$ exposure may impede EPC differentiation. Finally, Ccl5 (Rantes) is a pro-inflammatory cytokine released by early EPCs but to a much lesser 
extent by late EPCs [58]. The upregulation of $C c 15$ in EPCs derived from CAP-exposed mice (Tables 1 and 7) is consistent with the idea that these cells remain in an early, immature state, being inefficient in promoting vascular repair. Other DEGs we identified and confirmed by qRT-PCR (Itga3, Marcks, Dock9, Dusp-10; Tables 6 and 7) play general roles in cell adhesion, cytoskeletal organization, growth, and differentiation, and may likewise play essential roles in EPC mobilization, homing, migration, and tissue repair. Some of the DEGs and DE-miRNAs identified in our analysis (Tables 1-3) have an uncertain role in EPC function, and a delineation of their roles requires more sophisticated approaches in future studies. Nevertheless, the current work suggests $\mathrm{PM}_{2.5}$-induced changes in gene expression may underlie widespread functional defects in EPCs that could lead to impairments in vascular repair and promotion of CVD.

Our findings are significant because they show that $\mathrm{PM}_{2.5}$-induced gene expression changes can occur in a tissue (bone marrow) that is distal from the tissue of initial exposure (lungs). These long-range $\mathrm{PM}_{2.5}$ effects are believed to initiate largely from redox-catalyzed lipid peroxidation and the generation of toxic intermediates such as aldehydes in the lungs. These intermediates are then distributed systemically through peripheral blood circulation to impact the function of other tissues [59]. There is strong evidence that lipid peroxidation products and aldehydes can influence DNA methylation and histone acetylation patterns [60], as well as miRNA expression levels [61,62]. Thus, $\mathrm{PM}_{2.5}$-induced oxidative stress may be causative in the gene expression changes we observed. Supporting this idea, measures taken to limit oxidative stress [18,37], or to neutralize aldehydes [63], appear to limit the downstream, toxic effects of $\mathrm{PM}_{2.5}$ exposure and can reverse some of gene expression changes we previously observed [18].

One limitation of this study is that it is not clear if our results are applicable to all exposure scenarios, as $\mathrm{PM}_{2.5}$ concentration and composition may vary according to locale and in a seasonal and temporal manner. However, the location of our exposure facility in downtown Louisville assures that particles are derived from diverse and voluminous vehicle exhausts and are generally reflective of traffic-derived $\mathrm{PM}_{2.5}$ in any locale. Furthermore, with a 30-day exposure period, we expect the effects of daily variations in composition would be minimized. Consistent with this idea, the predicted biological functions impacted by the gene and miRNA expression changes we observed are consistent with air pollution-induced quantitative and qualitative defects in EPCs that have been previously reported [18,36,37].

\section{Conclusions}

In summary, we identified multiple changes in the expression of distinct mRNAs and miRNAs in bone marrow-derived EPCs isolated from mice inhaling CAP. Some of the predicted biological functions impacted by these changes are those regulating EPC availability or vascular repair potential. These results shed further mechanistic insight with regards to the origin of vascular pathologies associated with air pollution exposures in humans and add to the growing literature suggesting that environmental exposure to volatiles, metals, and chemicals impact health by inducing gene expression changes in diverse cell and tissue types [64-68].

Supplementary Materials: The following are available online at https:/ / www.mdpi.com/article/10 .3390/genes12071058/s1, Table S1. Summary of initial sequence analysis (mRNA). Table S2. Summary of initial sequence analysis (miRNA). Table S3. List of rtPCR primers used. Table S4. Upregulated genes. Listed are upregulated genes $\left(q<0.05 ; \log _{2} \mathrm{FC} \geq 0.6\right)$. Table S5. Downregulated genes. Listed are downregulated genes $\left(q<0.05 ;\left|\log _{2} \mathrm{FC}\right|>0.66\right)$.

Author Contributions: Conceptualization, P.H., D.J.C., A.B., and T.E.O.; methodology, P.H., D.J.C., and T.E.O.; software, X.L. and E.C.R.; validation, X.L., E.C.R., and T.E.O.; formal analysis, X.L., E.C.R., and T.E.O.; investigation, M.Z. and T.E.O.; resources, D.J.C., A.B., and T.E.O.; data curation, X.L., M.Z., and T.E.O.; writing-original draft preparation, X.L. and T.E.O.; writing-review and editing, X.L., P.H., D.J.C., A.B., and T.E.O.; visualization, X.L. and M.Z.; supervision, T.E.O.; project 
administration, A.B. and T.E.O.; funding acquisition, P.H., A.B., and T.E.O. All authors have read and agreed to the published version of the manuscript.

Funding: This research was funded by the National Institute of Health (R01 ES019217, P20GM103436, R01ES027881, R01ES028268, P20GM127607, P30ES030283). The funding body had no role in the design of the study and collection, analysis, and interpretation of the data, nor in the writing of the manuscript.

Institutional Review Board Statement: The study was conducted according to the guidelines of the Declaration of Helsinki, and approved by the University of Louisville Institutional Animal Care and Use Committee (\#14035; 9/8/17).

\section{Informed Consent Statement: Not applicable.}

Data Availability Statement: The sequence datasets supporting the conclusions of this article are available in the Gene Expression Omnibus (GEO) repository (https:/ /www.ncbi.nlm.nih.gov/geo/, accessed on 24 June 2020; accession number: GSE153038).

Acknowledgments: This work was performed with assistance of the UofL Genomics Facility and the Kentucky IDeA Networks of Biomedical Research Excellence. The authors thank Whitney Theis and Lexi Hand for their technical assistance.

Conflicts of Interest: The authors declare that they have no competing interests.

Institutional Animal Care and Use Committee: All animal procedures were approved by the University of Louisville Institutional Animal Care and Use Committee (\#14035).

\section{References}

1. Chen, H.; Goldberg, M.S.; Villeneuve, P.J. A systematic review of the relation between long-term exposure to ambient air pollution and chronic diseases. Rev. Environ. Health 2008, 23, 243-297.

2. Bhatnagar, A. Environmental cardiology: Studying mechanistic links between pollution and heart disease. Circ. Res. 2006, 99, 692-705. [CrossRef]

3. Pope, C.A., 3rd; Burnett, R.T.; Thurston, G.D.; Thun, M.J.; Calle, E.E.; Krewski, D. Cardiovascular mortality and long-term exposure to particulate air pollution: Epidemiological evidence of general pathophysio-logical pathways of disease. Circulation 2004, 109, 71-77. [CrossRef]

4. Künzli, N.; Jerrett, M.; Mack, W.J.; Beckerman, B.; LaBree, L.; Gilliland, F.; Thomas, D.; Peters, J.; Hodis, H.N. Ambient Air Pollution and Atherosclerosis in Los Angeles. Environ. Health Perspect. 2005, 113, 201-206. [CrossRef] [PubMed]

5. Pope, C.A., 3rd; Muhlestein, J.B.; May, H.T.; Renlund, D.G.; Anderson, J.L.; Horne, B.D. Ischemic heart disease events triggered by short-term exposure to fine particulate air pollution. Circulation 2006, 114, 2443-2448. [CrossRef] [PubMed]

6. Chen, H.; Burnett, R.T.; Kwong, J.C.; Villeneuve, P.J.; Goldberg, M.S.; Brook, R.D. Spatial association be-tween ambient fine particulate matter and incident hypertension. Circulation 2014, 129, 562-569. [CrossRef]

7. Krishnan, R.M.; Adar, S.D.; Szpiro, A.A.; Jorgensen, N.W.; Van Hee, V.C.; Barr, R.G. Vascular responses to long- and short-term exposure to fine particulate matter: MESA Air (Multi-Ethnic Study of Athero-sclerosis and Air Pollution). J. Am. Coll. Cardiol. 2012, 60, 2158-2166. [CrossRef]

8. Asahara, T.; Murohara, T.; Sullivan, A.; Silver, M.; van der Zee, R.; Li, T. Isolation of putative progenitor endothelial cells for angiogenesis. Science 1997, 275, 964-967. [CrossRef] [PubMed]

9. Fadini, G.P.; Losordo, D.; Dimmeler, S. Critical Reevaluation of Endothelial Progenitor Cell Phenotypes for Therapeutic and Diagnostic Use. Circ. Res. 2012, 110, 624-637. [CrossRef] [PubMed]

10. Reed, M.J.; Karres, N.; Eyman, D.; Edelberg, J. Endothelial Precursor Cells. Stem Cell Rev. Rep. 2007, 3, 218-225. [CrossRef]

11. Roberts, N.; Jahangiri, M.; Xu, Q. Progenitor cells in vascular disease. J. Cell. Mol. Med. 2005, 9, 583-591. [CrossRef]

12. Fadini, G.P.; De Kreutzenberg, S.V.; Coracina, A.; Baesso, I.; Agostini, C.; Tiengo, A.; Avogaro, A. Cir-culating CD34 ${ }^{+}$cells, metabolic syndrome, and cardiovascular risk. Eur. Hear. J. 2006, 27, 2247-2255. [CrossRef]

13. Hill, J.M.; Zalos, G.; Halcox, J.P.; Schenke, W.H.; Waclawiw, M.A.; Quyyumi, A.A. Circulating endothelial progenitor cells, vascular function, and cardiovascular risk. N. Engl. J. Med. 2003, 348, 593-600. [CrossRef]

14. Vasa, M.; Fichtlscherer, S.; Aicher, A.; Adler, K.; Urbich, C.; Martin, H. Number and migratory activity of circulating endothelial progenitor cells inversely correlate with risk factors for coronary artery disease. Circ. Res. 2001, 89, E1-E7. [CrossRef]

15. Werner, N.; Kosiol, S.; Schiegl, T.; Ahlers, P.; Walenta, K.; Link, A.; Bohm, M.C.; Nickenig, G. Circulat-ing Endothelial Progenitor Cells and Cardiovascular Outcomes. N. Engl. J. Med. 2005, 353, 999-1007. [CrossRef]

16. Haberzettl, P.; Lee, J.; Duggineni, D.; McCracken, J.; Bolanowski, D.; O’Toole, T.E. Exposure to ambient air fine particulate matter prevents VEGF-induced mobilization of endothelial progenitor cells from the bone marrow. Environ. Health Perspect. 2012, 120, 848-856. [CrossRef] 
17. O’Toole, T.E.; Hellmann, J.; Wheat, L.; Haberzettl, P.; Lee, J.; Conklin, D.J.; Bhatnagar, A.; Pope, I.C.A. Episodic Exposure to Fine Particulate Air Pollution Decreases Circulating Levels of Endothelial Progenitor Cells. Circ. Res. 2010, 107, 200-203. [CrossRef] [PubMed]

18. Haberzettl, P.; Conklin, D.J.; Abplanalp, W.T.; Bhatnagar, A.; O’Toole, T.E. Inhalation of Fine Particu-late Matter Impairs Endothelial Progenitor Cell Function via Pulmonary Oxidative Stress. Arter. Thromb. Vasc. Biol. 2018, 38, 131-142. [CrossRef]

19. Heiss, C.; Amabile, N.; Lee, A.C.; Real, W.M.; Schick, S.F.; Lao, D.; Wong, M.L.; Jahn, S.; Angeli, F.S.; Minasi, P.; et al. Brief Secondhand Smoke Exposure Depresses Endothelial Progenitor Cells Activity and Endothelial Function: Sustained Vascular Injury and Blunted Nitric Oxide Production. J. Am. Coll. Cardiol. 2008, 51, 1760-1771. [CrossRef] [PubMed]

20. Jantzen, K.; Jensen, A.; Kermanizadeh, A.; Elholm, G.; Sigsgaard, T.; Møller, P.; Roursgaard, M.; Loft, S. Inhalation of House Dust and Ozone Alters Systemic Levels of Endothelial Progenitor Cells, Oxidative Stress, and Inflammation in Elderly Subjects. Toxicol. Sci. 2018, 163, 353-363. [CrossRef]

21. Jiang, Y.; Wang, L.-P.; Dong, X.-H.; Cai, J.; Jiang, G.-J.; Zhang, C.; Xie, H.-H. Trace Amounts of Cop-per in Drinking Water Aggravate Cerebral Ischemic Injury via Impairing Endothelial Progenitor Cells in Mice. CNS Neurosci. Ther. 2015, 21, 677-680. [CrossRef] [PubMed]

22. Wheat, L.A.; Haberzettl, P.; Hellmann, J.; Baba, S.P.; Bertke, M.; Lee, J.; McCracken, J.; O’Toole, T.E.; Bhatnagar, A.; Conklin, D.J. Acrolein Inhalation Prevents Vascular Endothelial Growth Factor-Induced Mobilization of Flk-1 + /Sca-1 + Cells in Mice. Arter. Thromb. Vasc. Biol. 2011, 31, 1598-1606. [CrossRef] [PubMed]

23. Dobin, A.; Davis, C.A.; Schlesinger, F.; Drenkow, J.; Zaleski, C.; Jha, S.; Batut, P.; Chaisson, M.; Gingeras, T.R. STAR: Ultrafast universal RNA-seq aligner. Bioinformatics 2013, 29, 15-21. [CrossRef]

24. Love, M.I.; Huber, W.; Anders, S. Moderated estimation of fold change and dispersion for RNA-seq data with DESeq2. Genome Biol. 2014, 15, 550. [CrossRef]

25. Bolger, A.M.; Lohse, M.; Usadel, B. Trimmomatic: A flexible trimmer for Illumina sequence data. Bioinformatics 2014, 30, 2114-2120. [CrossRef]

26. Friedlander, M.; Mackowiak, S.; Li, N.; Chen, W.; Rajewsky, N. miRDeep2 accurately identifies known and hundreds of novel microRNA genes in seven animal clades. Nucleic Acids Res. 2011, 40, 37-52. [CrossRef]

27. Langmead, B.; Salzberg, S.L. Fast gapped-read alignment with Bowtie 2. Nat. Methods 2012, 9, 357-359. [CrossRef]

28. Livak, K.J.; Schmittgen, T.D. Analysis of relative gene expression data using real-time quantitative PCR and the 2(-Delta Delta C(T)) Method. Methods 2001, 25, 402-408. [CrossRef]

29. Chen, H.; Yao, X.; Di, X.; Zhang, Y.; Zhu, H.; Liu, S.; Chen, T.; Yu, D.; Sun, X. MiR-450a-5p inhibits autophagy and enhances radiosensitivity by targeting dual-specificity phosphatase 10 in esophageal squa-mous cell carcinoma. Cancer Lett. 2020, 483, 114-126. [CrossRef]

30. Chou, C.H.; Chang, N.W.; Shrestha, S.; Hsu, S.D.; Lin, Y.L.; Lee, W.H. miRTarBase 2016: Updates to the experimentally validated miRNA-target interactions database. Nucleic Acids Res. 2016, 44, D239-D247. [CrossRef]

31. Mitra, A.K.; Zillhardt, M.; Hua, Y.; Tiwari, P.; Murmann, A.E.; Peter, M.E.; Lengyel, E. MicroRNAs Reprogram Normal Fibroblasts into Cancer-Associated Fibroblasts in Ovarian Cancer. Cancer Discov. 2012, 2, 1100-1108. [CrossRef]

32. Wiese, C.B.; Zhong, J.; Xu, Z.Q.; Zhang, Y.; Solano, M.A.R.; Zhu, W. Dual inhibition of endothelial miR-92a-3p and miR-489-3p reduces renal injury-associated atherosclerosis. Atherosclerosis 2019, 282, 121-131. [CrossRef]

33. Haberzettl, P.; O'Toole, T.E.; Bhatnagar, A.; Conklin, D.J. Exposure to Fine Particulate Air Pollution Caus-es Vascular Insulin Resistance by Inducing Pulmonary Oxidative Stress. Environ. Health Perspect. 2016, 124, 1830-1839. [CrossRef]

34. Sun, Q.; Wang, A.; Jin, X.; Natanzon, A.; Duquaine, D.; Brook, R.D.; Aguinaldo, J.-G.S.; Fayad, Z.A.; Fuster, V.; Lippmann, M.; et al. Long-term Air Pollution Exposure and Acceleration of Atherosclerosis and Vascular Inflammation in an Animal Model. JAMA 2005, 294, 3003-3010. [CrossRef]

35. Suwa, T.; Hogg, J.C.; Quinlan, K.B.; Ohgami, A.; Vincent, R.; van Eeden, S.F. Particulate air pollution induces progression of atherosclerosis. J. Am. Coll. Cardiol. 2002, 39, 935-942. [CrossRef]

36. Liberda, E.N.; Cuevas, A.K.; Gillespie, P.A.; Grunig, G.; Qu, Q.; Chen, L.C. Exposure to inhaled nickel nanoparticles causes a reduction in number and function of bone marrow endothelial progenitor cells. Inhal. Toxicol. 2010, 22 (Suppl. 2), 95-99. [CrossRef]

37. Cui, Y.; Jia, F.; He, J.; Xie, X.; Li, Z.; Fu, M. Ambient Fine Particulate Matter Suppresses In Vivo Pro-lif-eration of Bone Marrow Stem Cells through Reactive Oxygen Species Formation. PLoS ONE 2015, 10, e0127309. [CrossRef]

38. Huang, Y.; Guo, Z.-Q.; Zhang, R.-X.; Zhao, R.-W.; Dong, W.-Y.; Wang, H.; Deng, C.-R.; Zhuang, G.-S. Effect of PM2.5 on MicroRNA Expression and Function in Nasal Mucosa of Rats with Allergic Rhinitis. Am. J. Rhinol. Allergy 2020, 34, 543-553. [CrossRef] [PubMed]

39. Rodosthenous, R.S.; Coull, B.A.; Lu, Q.; Vokonas, P.S.; Schwartz, J.D.; Baccarelli, A.A. Ambient particulate matter and microRNAs in extracellular vesicles: A pilot study of older individuals. Part. Fibre Toxicol. 2016, 13, 13. [CrossRef]

40. He, X.; Chen, Y.; Zhang, C.; Gong, W.; Zhang, X.; Nie, S. Polycyclic Aromatic Hydrocarbons from Particulate Matter 2.5 (PM2.5) in Polluted Air Changes miRNA Profile Related to Cardiovascular Disease. Med. Sci. Monit. 2018, 24, 5925-5934. [CrossRef]

41. Wang, Y.; Zou, L.; Wu, T.; Xiong, L.; Zhang, T.; Kong, L. Identification of mRNA-miRNA crosstalk in human endothelial cells after exposure of PM2.5 through integrative transcriptome analysis. Ecotoxicol. Environ. Saf. 2019, 169, 863-873. [CrossRef]

42. Allis, C.D.; Jenuwein, T. The molecular hallmarks of epigenetic control. Nat. Rev. Genet. 2016, 17, 487-500. [CrossRef] 
43. Chi, G.C.; Liu, Y.; MacDonald, J.W.; Barr, R.G.; Donohue, K.M.; Hensley, M.D. Long-term outdoor air pollution and DNA methylation in circulating monocytes: Results from the Multi-Ethnic Study of Ather-osclerosis (MESA). Environ. Health 2016, 15, 119. [CrossRef]

44. Ding, R.; Jin, Y.; Liu, X.; Zhu, Z.; Zhang, Y.; Wang, T.; Xu, Y. Characteristics of DNA methylation changes induced by traffic-related air pollution. Mutat. Res. Toxicol. Environ. Mutagen. 2016, 796, 46-53. [CrossRef]

45. Wei, H.; Liang, F.; Meng, G.; Nie, Z.; Zhou, R.; Cheng, W.; Wu, X.; Feng, Y.; Wang, Y. Redox/methylation mediated abnormal DNA methylation as regulators of ambient fine particulate matter-induced neurodevelopment related impairment in human neuronal cells. Sci. Rep. 2016, 6, 33402. [CrossRef]

46. Li, Y.; Zhou, J.; Rui, X.; Zhou, L.; Mo, X. PM2.5 exposure exacerbates allergic rhinitis in mice by increasing DNA methylation in the IFN-gamma gene promoter in CD4+T cells via the ERK-DNMT pathway. Toxicol. Lett. 2019, 301, 98-107. [CrossRef]

47. Wu, Q.; Ni, X. ROS-mediated DNA methylation pattern alterations in carcinogenesis. Curr. Drug. Targets. 2015, 16, 13-19. [CrossRef]

48. Ghio, A.J.; Carraway, M.S.; Madden, M.C. Composition of Air Pollution Particles and Oxidative Stress in Cells, Tissues, and Living Systems. J. Toxicol. Environ. Health Part B 2012, 15, 1-21. [CrossRef]

49. Zong, D.; Liu, X.; Li, J.; Ouyang, R.; Chen, P. The role of cigarette smoke-induced epigenetic alterations in inflammation. Epigenetics Chromatin 2019, 12, 1-25. [CrossRef]

50. Jimenez-Garza, O.; Guo, L.; Byun, H.M.; Carrieri, M.; Bartolucci, G.B.; Barron-Vivanco, B.S. Aberrant promoter methylation in genes related to hematopoietic malignancy in workers exposed to a VOC mixture. Toxicol. Appl. Pharmacol. 2018, 339, 65-72. [CrossRef]

51. Martin, E.M.; Fry, R.C. Environmental Influences on the Epigenome: Exposure-Associated DNA Meth-ylation in Human Populations. Annu. Rev. Public Health 2018, 39, 309-333. [CrossRef]

52. Ding, R.; Jin, Y.; Liu, X.; Zhu, Z.; Zhang, Y.; Wang, T.; Xu, Y. H3K9 acetylation change patterns in rats after exposure to traffic-related air pollution. Environ. Toxicol. Pharmacol. 2016, 42, 170-175. [CrossRef] [PubMed]

53. Liu, C.; Xu, J.; Chen, Y.; Guo, X.; Zheng, Y.; Wang, Q.; Chen, Y.; Ni, Y.; Zhu, Y.; Joyce, B.T.; et al. Characterization of genome-wide H3K27ac profiles reveals a distinct PM2.5-associated histone modification signature. Environ. Health 2015, 14, 65. [CrossRef]

54. Hou, Y.; Plett, P.A.; Ingram, D.A.; Rajashekhar, G.; Orschell, C.M.; Yoder, M.; March, K.L.; Clauss, M. Endothelial-monocyteactivating polypeptide II induces migration of endothelial progenitor cells via the chemokine receptor CXCR3. Exp. Hematol. 2006, 34, 1125-1132. [CrossRef] [PubMed]

55. Ling, C.-C.; Ng, K.T.-P.; Shao, Y.; Geng, W.; Xiao, J.-W.; Liu, H.; Li, C.-X.; Liu, X.-B.; Ma, Y.-Y.; Yeung, W.-H.; et al. Post-transplant endothelial progenitor cell mobilization via CXCL10/CXCR3 signaling promotes liver tumor growth. J. Hepatol. 2014, 60, 103-109. [CrossRef] [PubMed]

56. Siavashi, V.; Nassiri, S.M.; Rahbarghazi, R.; Mohseni, Z.; Sharifi, A.M. Distinct Tie2 tyrosine phosphorylation sites dictate phenotypic switching in endothelial progenitor cells. J. Cell. Physiol. 2019, 234, 6209-6219. [CrossRef]

57. Takahashi, K.; Yamanaka, S. Induction of pluripotent stem cells from mouse embryonic and adult fibroblast cultures by defined factors. Cell 2006, 126, 663-676. [CrossRef]

58. Zhang, Y.; Ingram, D.A.; Murphy, M.P.; Saadatzadeh, M.R.; Mead, L.E.; Prater, D.N. Release of proinflammatory mediators and expression of proinflammatory adhesion molecules by endothelial progenitor cells. Am. J. Physiol. Heart Circ. Physiol. 2009, 296, H1675-H1682. [CrossRef] [PubMed]

59. Kampfrath, T.; Maiseyeu, A.; Ying, Z.; Shah, Z.; Deiuliis, J.A.; Xu, X. Chronic fine particulate matter exposure induces systemic vascular dysfunction via NADPH oxidase and TLR4 pathways. Circ. Res. 2011, 108, 716-726. [CrossRef]

60. Eckl, P.M.; Bresgen, N. Genotoxicity of lipid oxidation compounds. Free. Radic. Biol. Med. 2017, 111, 244-252. [CrossRef]

61. O'Toole, T.E.; Abplanalp, W.; Li, X.; Cooper, N.; Conklin, D.J.; Haberzettl, P. Acrolein decreases endothelial cell migration and insulin sensitivity through induction of let-7a. Toxicol. Sci. 2014, 140, 271-282. [CrossRef]

62. Pizzimenti, S.; Ferracin, M.; Sabbioni, S.; Toaldo, C.; Pettazzoni, P.; Dianzani, M.U. MicroRNA expression changes during human leukemic HL-60 cell differentiation induced by 4-hydroxynonenal, a product of lipid peroxidation. Free Radic. Biol. Med. 2009, 46, 282-288. [CrossRef]

63. Abplanalp, W.; Haberzettl, P.; Bhatnagar, A.; Conklin, D.J.; O’Toole, T.E. Carnosine Supplementation Mitigates the Deleterious Effects of Particulate Matter Exposure in Mice. J. Am. Heart Assoc. 2019, 8, e013041. [CrossRef]

64. Brody, J.S. Transcriptome alterations induced by cigarette smoke. Int. J. Cancer 2012, 131, 2754-2762. [CrossRef]

65. Chappell, G.; Pogribny, I.P.; Guyton, K.Z.; Rusyn, I. Epigenetic alterations induced by genotoxic occupational and environmental human chemical carcinogens: A systematic literature review. Mutat. Res. Rev. Mutat. Res. 2016, 768, 27-45. [CrossRef]

66. Kopa, P.N.; Pawliczak, R. Effect of smoking on gene expression profile-Overall mechanism, impact on respiratory system function, and reference to electronic cigarettes. Toxicol. Mech. Methods 2018, 28, 397-409. [CrossRef]

67. Mohanty, B.P.; Mahanty, A.; Mitra, T.; Mohanty, S.; Naik, A.K.; Parija, S.C. Proteomic and tran-scriptomic changes in rat liver following oral feeding of formaldehyde. Chemosphere 2020, 245, 125599. [CrossRef]

68. Wallace, D.R.; Taalab, Y.; Heinze, S.; Lovaković, B.T.; Pizent, A.; Renieri, E.; Tsatsakis, A.; Farooqi, A.A.; Javorac, D.; Andjelkovic, M.; et al. Toxic-Metal-Induced Alteration in miRNA Expression Profile as a Proposed Mechanism for Disease Development. Cells 2020, 9, 901. [CrossRef] 